\title{
Drawing the history of the Hutterite population on a genetic landscape: inference from Y-chromosome and mtDNA genotypes
}

Irene Pichler, Christian Fuchsberger, Christa Platzer, Minal Çalişkan, Fabio Marroni, Peter P Pramstaller and Carole Ober European Journal of Human Genetics (2010) 18, 509; doi:10.1038/ejhg.2009.208

Correction to: European Journal of Human Genetics (2010) 18, 463-470; doi: 10.1038/ejhg.2009.172; published online 21 October 2009

Since the online publication of the above paper, the authors noticed that the affiliations are incorrect. The correct affiliations are listed below.

Irene Pichler ${ }^{1}$, Christian Fuchsberger ${ }^{1}$, Christa Platzer $^{1}$, Minal Çalişkan ${ }^{2}$, Fabio Marroni ${ }^{1}$, Peter P Pramstaller ${ }^{1,3,4}$ and Carole Ober ${ }^{2}$
${ }^{1}$ Institute of Genetic Medicine, European Academy Bozen/Bolzano (EURAC), Bolzano, Italy (Affiliated Institute of the University of Lübeck, Germany); ${ }^{2}$ Department of Human Genetics, The University of Chicago, Chicago, IL 60637, USA; ${ }^{3}$ Department of Neurology, University of Lübeck, Lübeck, Germany; ${ }^{4}$ Department of Neurology, Central Regional Hospital, Bolzano, Italy

The authors would like to apologise for this mistake.

\section{Differential $\mathbf{M S H 2}$ promoter methylation in blood cells of Neurofibromatosis type 1 (NF1) patients}

Sabrina Titze, Hartmut Peters, Sandra Währisch, Thomas Harder, Katrin Guse, Annegret Buske, Sigrid Tinschert and Anja Harder

European Journal of Human Genetics (2010) 18, 509; doi:10.1038/ejhg.2010.6

Correction to: European Journal of Human Genetics 18: 81-87; doi:10.1038/ejhg.2009.129; published online 29 July 2009

Since the publication of the above article, the authors noticed two errors. First, Figure 3 is incorrect (in fact, by mistake the same data as in Table 2 are shown here). The correct Figure 3 is reproduced below.

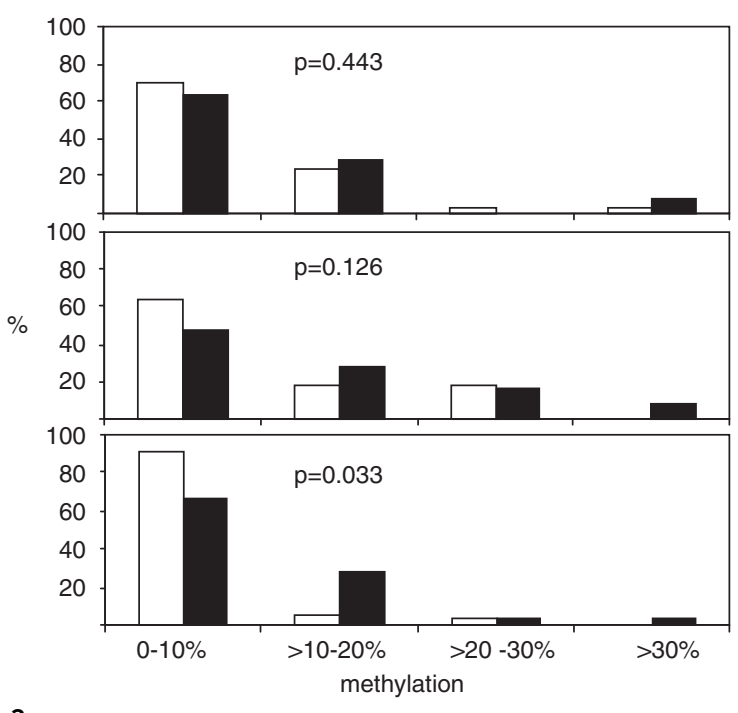

Figure 3
Second, the authors would like to correct a numerical error. Position $-68 \mathrm{nt}$ of $\mathrm{MSH} 2$ (Materials and methods section, legend of Figure 2) should be $-62 \mathrm{nt}$.

The authors would like to apologise for this mistake.

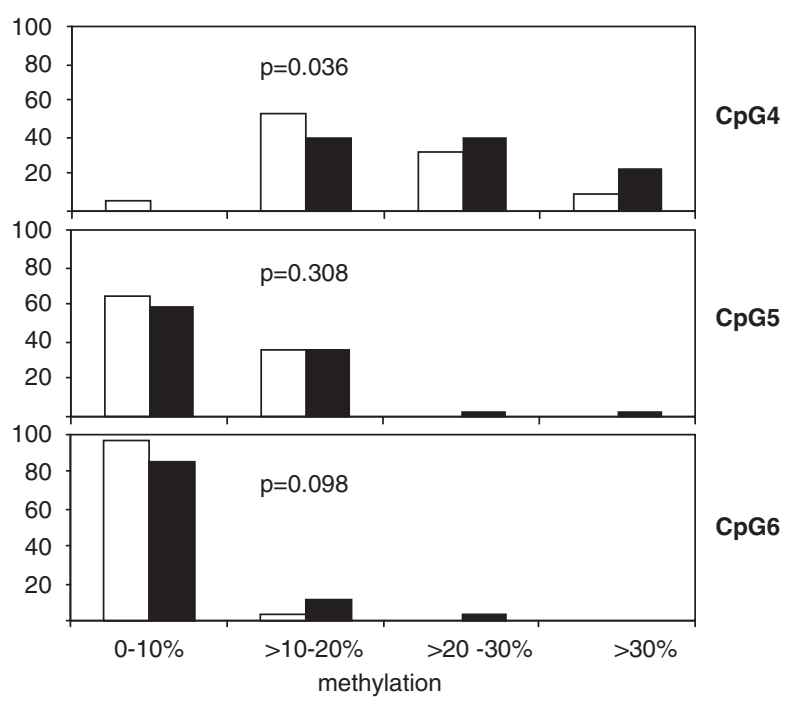

